\title{
Performance Evaluation of Solar Rooftop System
}

\author{
Apichart Yodkhuang ${ }^{\mathrm{a}}$, Atthapol Ngaopitakkul ${ }^{\mathrm{a}^{*}}$ \\ ${ }^{a}$ Faculty of Engineering, King Mongkut's Institute of Technology Ladkrabang, \\ Chalongkrung Road, Ladkrabang, Bangkok, 10520, Thailand \\ *Corresponding Author: knatthap@kmitl.ac.th
}

\begin{abstract}
In the recent trend of renewable energy, photovoltaic (PV) has gained a lot of attention from government and private investors due to reduction of technology cost and support policy from government. Number solar rooftop system in residential sector in Thailand has been rapidly increased in term of installing capacity in these last few years. So, this paper aims to study performance of solar rooftop system. Factors affecting generating capacity of solar panel has been taken into account such as climate, temperature and solar radiation. Three types of solar panel have been used in research: monocrystalline, polycrystalline and thin-film. To evaluate the effect of weather on solar rooftop system and maximum power generating, capacity power and energy that solar rooftop system can generat have been measured.
\end{abstract}

Keywords- Photovoltaic, Solar Rooftop, Solar irradiation, performance.

\section{INTRODUCTION}

Solar (PV) rooftop system in Thailand has recently gained much attention from an investor due to recent policy from Thai government "Solar Rooftop Programme" (1). These program supports community and resident to install solar system on their roof to further increase solar rooftop capacity of the country. Even through solar rooftop system has many advantages in terms of economical and environmental, impacts, many factors can affect solar rooftop system performance such as direction of sunlight, climate, temperature, solar radiation, and etc. In gird-connected solar rooftop system in residential area consists of solar panel to generate DC output, inverter to convert DC to AC for distribution grid and revenue meter to measure amount of electricity sold to electrical provider. Single line diagram of the system is show in Fig. 1.

Many researches and case studies about solar rooftop have been reviewed. For an effect of climate on PV performance, Koussa and et al. research ${ }^{(2-3)}$ has evaluated long-term performances of a solar systems using Algerian weather data. In Florida, it also has a long-term studies to evaluate the performance of solar system under humid climate (4). The study in potential of solar energy in residential sector of Spain ${ }^{(5)}$ has shown that solar rooftop system capacity in city can satisfy $80 \%$ of energy need. In Taiwan, a study to evaluate solar rooftop capacity and power generating in different zones to find suitable location for installing solar rooftop system ${ }^{(6)}$ was done. In Jung Hus So and et al. ${ }^{(7)}$ paper, they have presented estimation method for evaluating PV performance. In Thailand, we also have many researches trying to evaluate performance and effect of temperature and irradiance ${ }^{(8-10)}$. From these case studies, it can be seen that weather condition has a significant effect on solar rooftop power generating capacity.

In this paper, it aims to evaluate performance of solar (PV) rooftop system under various weather conditions. Main parameters focused in this research are temperature and solar radiation. Three types of solar panel have been used in experiment: monocrystalline, polycrystalline, and thin-film. The effect of weather condition on solar rooftop performance needs to be taken into consideration to ensure that solar rooftop system has generating capacity that benefits for both investor and electricity provider.

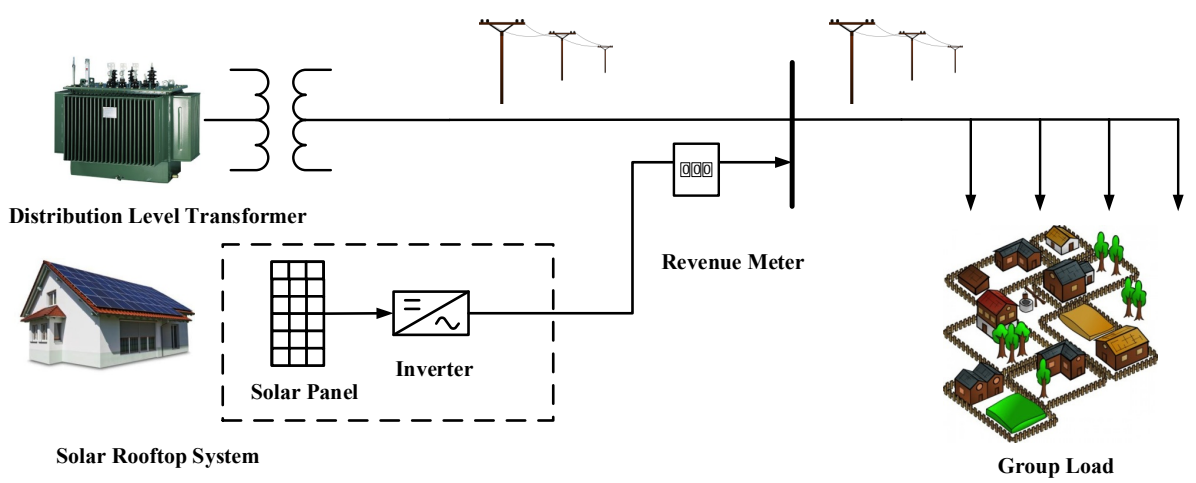

Fig. 1 Grid-connected solar rooftop system in residential area 


\section{EXPERIMENTAL SETUP}

This study aims to evaluate the performance of solar rooftop system with different types of solar panel under various weather conditions. Experimental setup is shown in Fig. 2. The system consists of Solar Array Simulator (number 1 in Fig. 2) that is capable of generating DC power, similar to real photovoltaic (PV) panel and able to import weather data in terms of temperature and solar irradiance into calculation process. An example of I-V curve of solar panel and weather data are shown in Fig. 3.

Fig. 3(a) shows I-V curve of monocrystalline solar panel and Fig. 3(b) shows temperature and irradiation in sunny day. This simulator connected to single phase inverter (number 2 in Fig. 2) to convert from DC to AC. System main parameters such as voltage, current, average power, energy and etc. are measured with power quality meter (number 3 in Fig. 2) before connected to distribution grid (number 4 in Fig. 2).

1. Solar Array Simulator

2. Inverter

3. Power Quality Meter

4. Distribution Grid

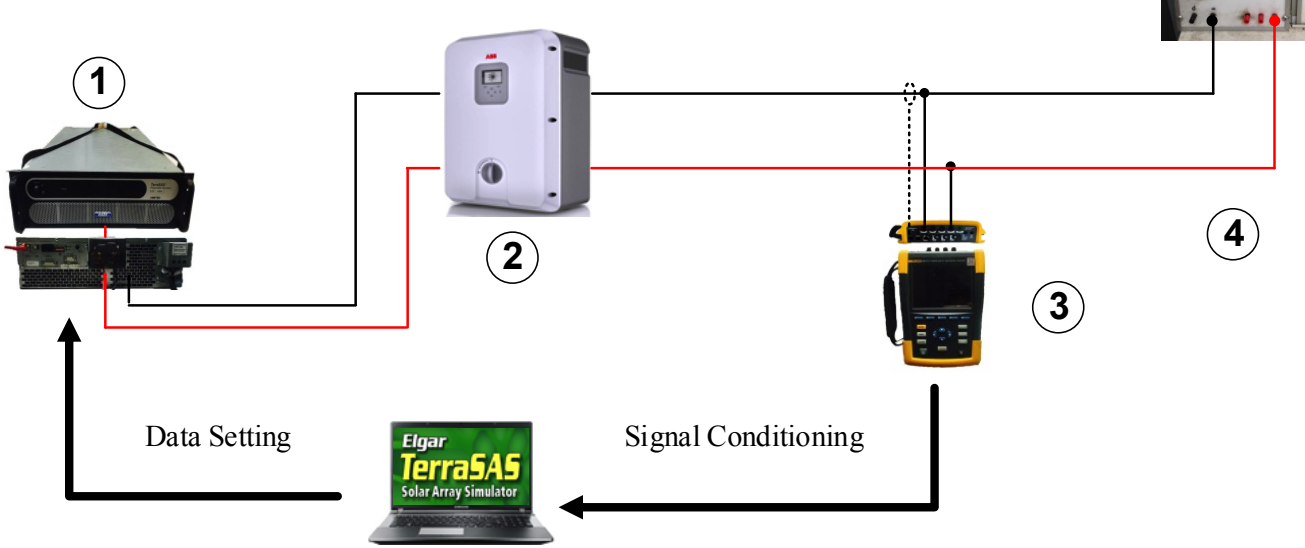

Fig. 2 Diagram of solar rooftop experimental setup

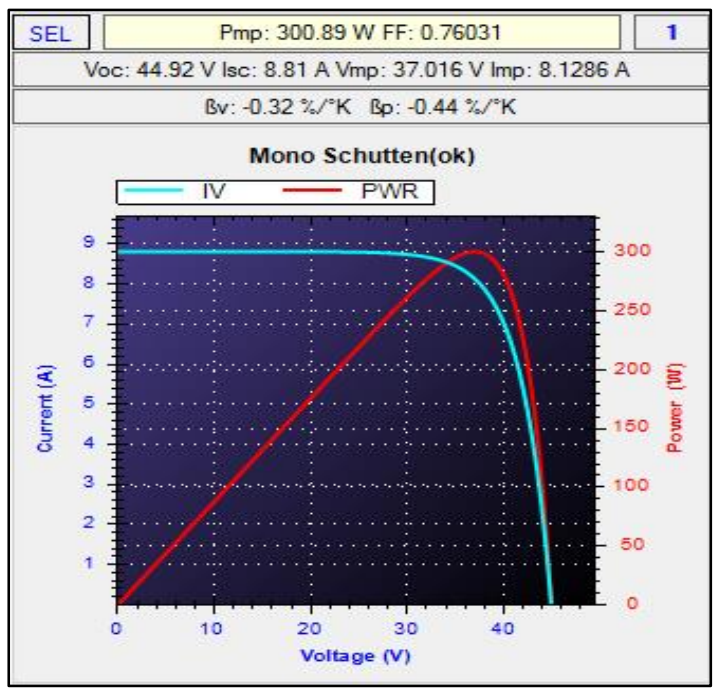

(a) I-V curve of Photovoltaic (PV) panel

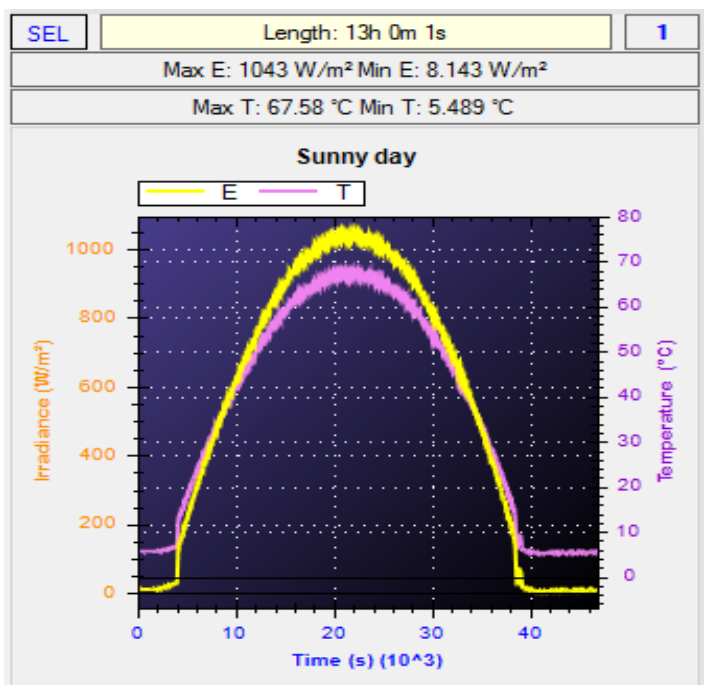

(b) Tempurate and irradiance profile

Fig. 3 Photovoltaic panel and weather data in TerraSAS Program 


\section{RESUlts}

From the experimental setup, power and energy that solar rooftop system can generate are measured from power quality meter as shown in Tables 1-2 and Figs 4-6. In Figs. 4-6, they show power and energy curves that solar rooftop system with different types of solar panel can generate in various weather conditions. In Fig. 4(a)-(c) show generate power and energy of monocrystalline solar panel in sunny, cloudy and rainy weather, respectively. It can be seen from the curve that in sunny weather power generated from solar rooftop system has followed the trend of sun movement throughout the day because in this case, nothing does block irradiation from the sun while energy has been steadily increased as the time passed. In cloudy weather, power has decreased in morning period due to the cloud shadow on solar panel. Energy curve has different slopes due to less energy generated in that time period. In rainy weather, power generated from solar rooftop system has dropped down significantly and energy curve has a stop point in the period that solar rooftop generates low power.
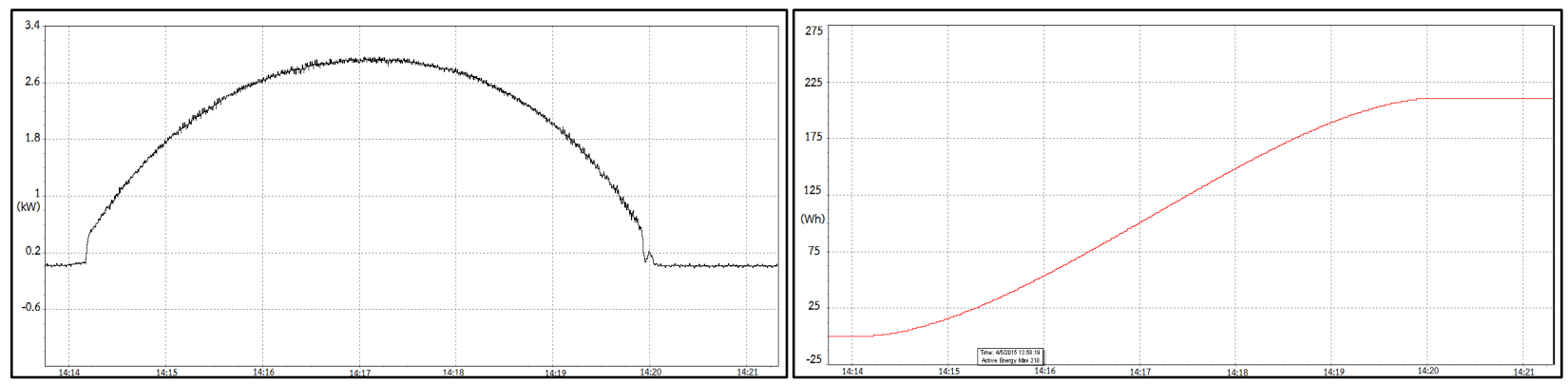

a). power $(\mathrm{kW})$ and energy $(\mathrm{kWh})$ generated in sunny weather
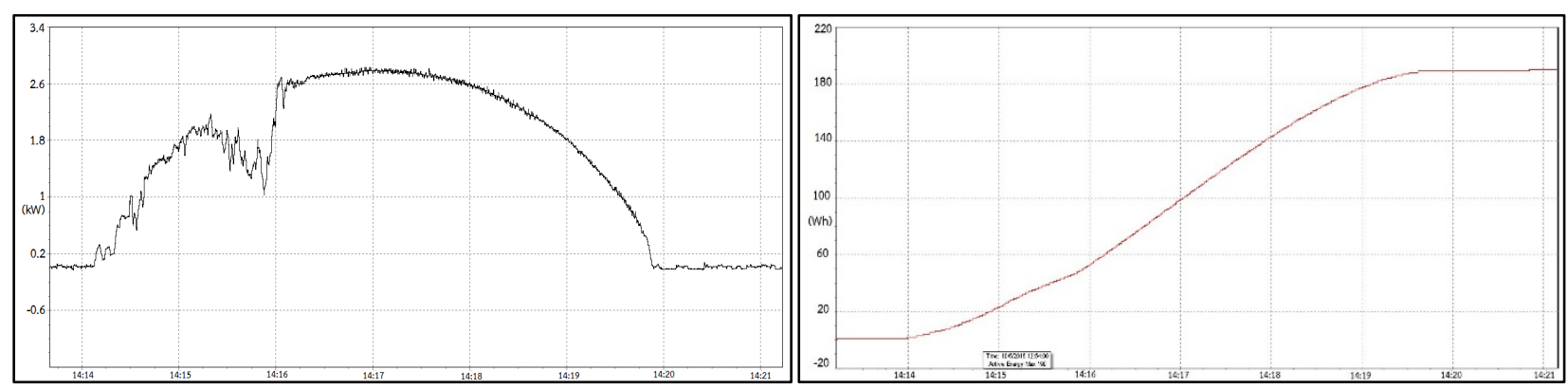

b). power $(\mathrm{kW})$ and energy $(\mathrm{kWh})$ generated in cloudy weather

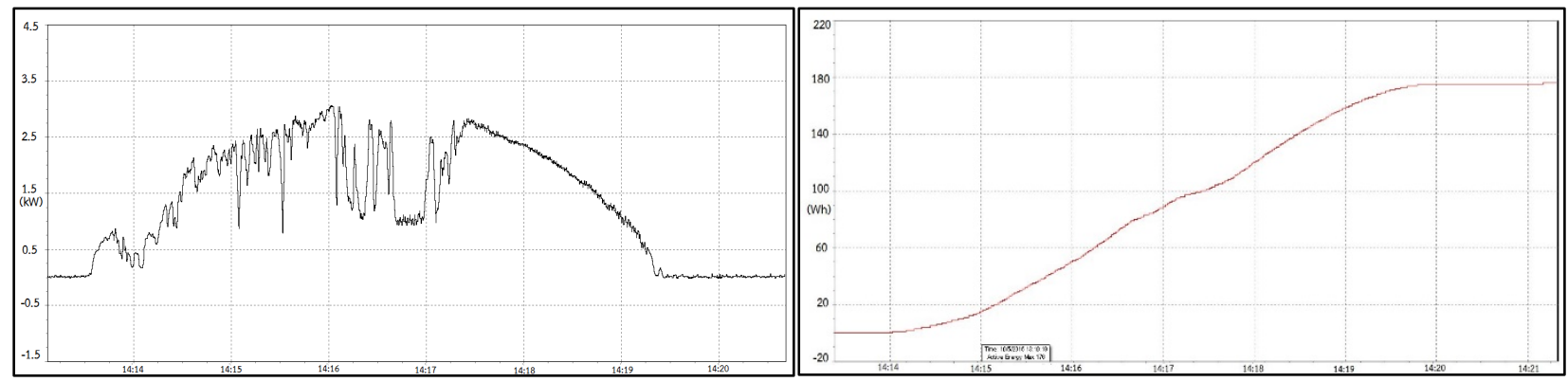

c). power $(\mathrm{kW})$ and energy $(\mathrm{kWh})$ generated in rainy weather

Fig. 4 Performance of monocrystalline type solar panel in various weather conditions. 


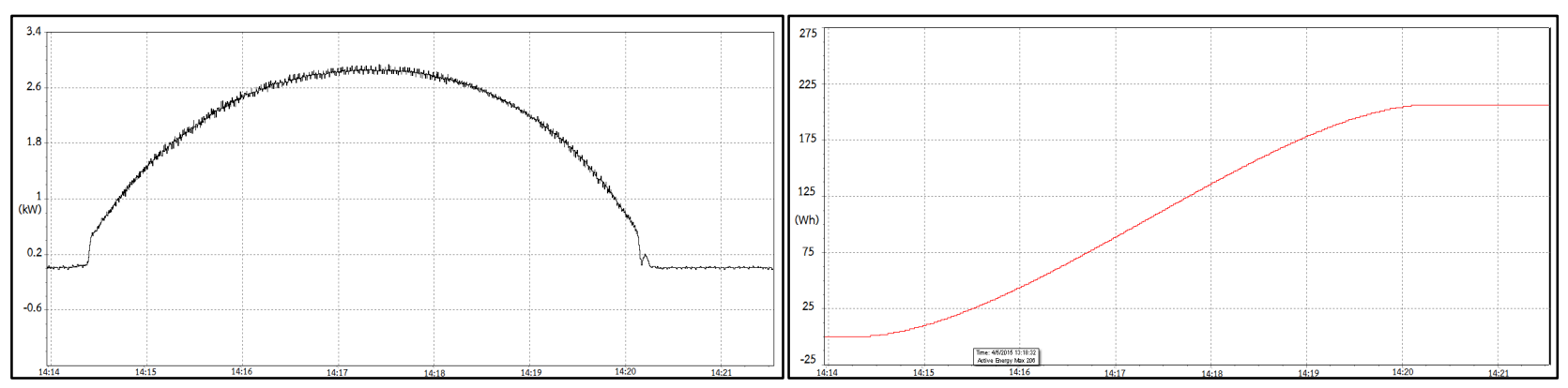

a). power $(\mathrm{kW})$ and energy $(\mathrm{kWh})$ generated in sunny weather

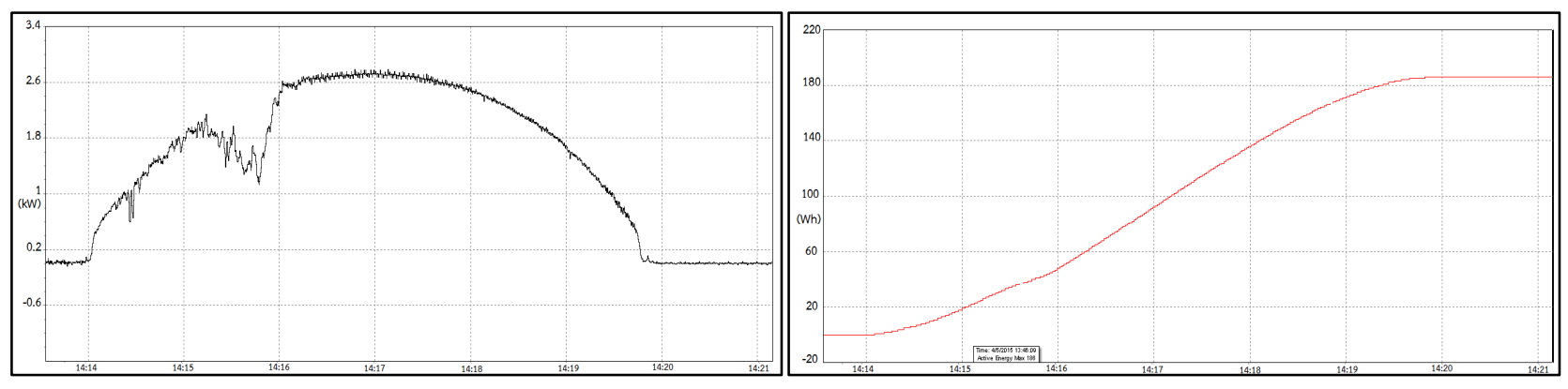

b). power $(\mathrm{kW})$ and energy $(\mathrm{kWh})$ generated in cloudy weather
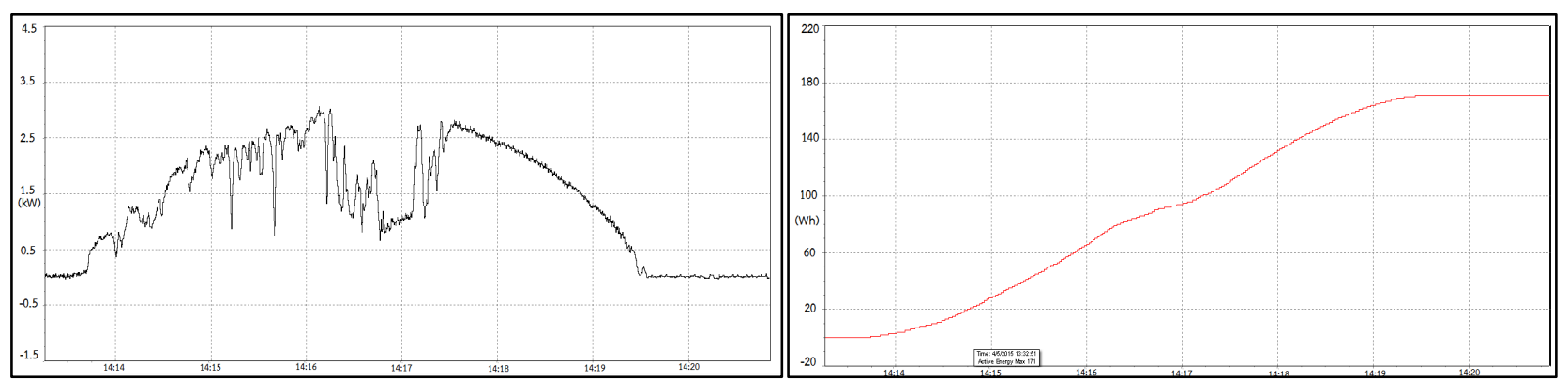

c). power $(\mathrm{kW})$ and energy $(\mathrm{kWh})$ generated in rainy weather

Fig. 5 Performance of polycrystalline type solar panel in various weather conditions.

Fig. 5(a)-(c) show generated power and energy of polycrystalline solar panel in sunny, cloudy and rainy weather, respectively. Power and energy curves in these case studies follow the trend of monocrystalline case with slightly difference in amount of power and energy that solar panel can generate.

Fig. 6(a)-(c) show generated power and energy of thinfilm solar panel in sunny, cloudy and rainy weather, respectively. Power and energy curves also follow the trend of first two case studies with slightly difference as seen in Fig. 6(c); it can generate more power in worse weather condition period than other solar panel. It remains efficient when weather is variant.
In Table 1, it shows average power and energy that each type of solar panel can generate in one day and its performance under various weather conditions. Monocrystalline has better generating capacity than other type of solar panel and thin-film type has lowest generating capacity. Table 2 has shown efficiency of each type of solar panel under various weather conditions compared to sunny day. It can be seen that thin-film type solar panel has better efficiency when temperature and irradiation are dropped down due to cloudy or rainy day. While monocrystalline and polycrystalline have relatively similar efficiency. 

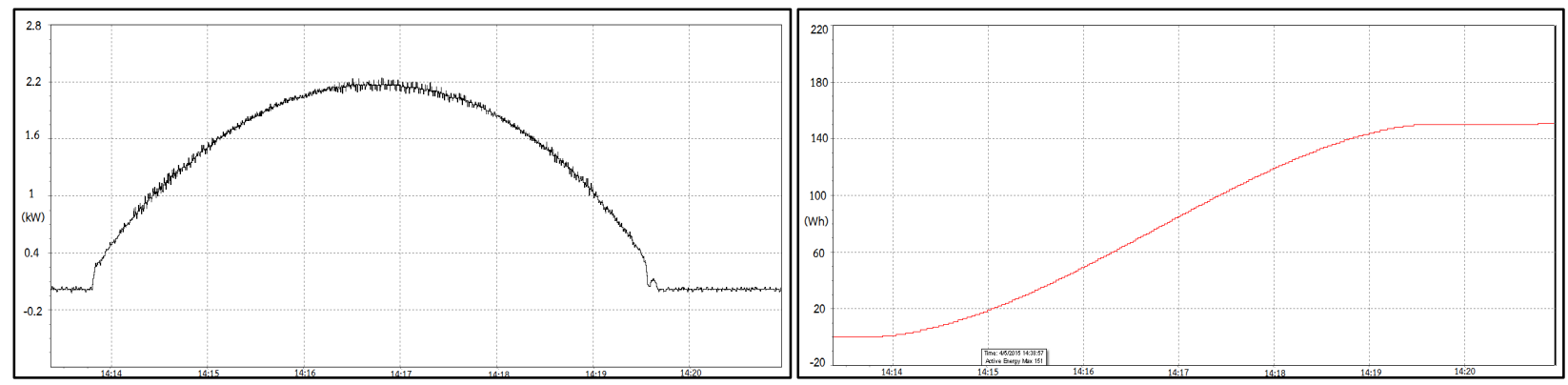

a). power $(\mathrm{kW})$ and energy $(\mathrm{kWh})$ generated in sunny weather
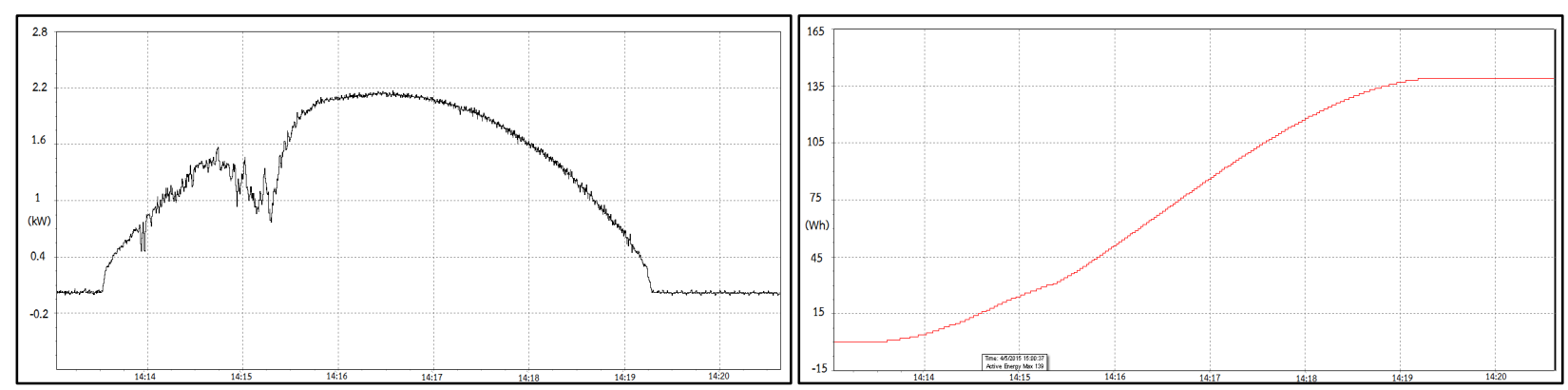

b). power $(\mathrm{kW})$ and energy $(\mathrm{kWh})$ generated in cloudy weather
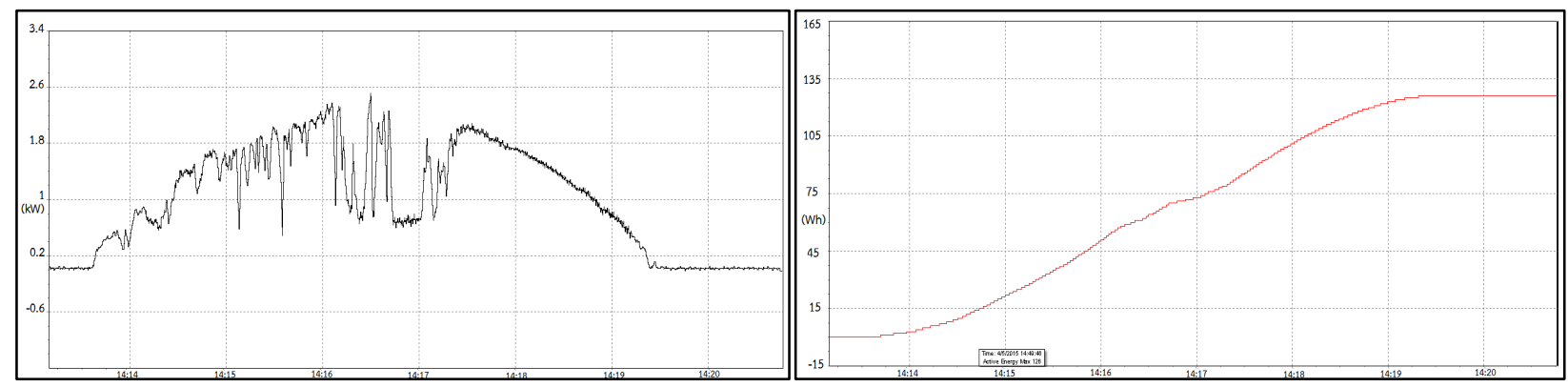

c). power $(\mathrm{kW})$ and energy $(\mathrm{kWh})$ generated in rainy weather

Fig. 6 Performance of thin-film type solar panel in various weather conditions.

Table 1. Average Power and Energy Generated from different types of solar panel in various weather conditions

\begin{tabular}{|c|c|c|c|c|c|c|}
\hline \multirow{3}{*}{ Weather } & \multicolumn{3}{|c|}{ Solar Panel } \\
\cline { 2 - 7 } & \multicolumn{2}{|c|}{ Monocrystalline } & \multicolumn{2}{c|}{ Polycrystalline } & \multicolumn{2}{c|}{ Thin-Film } \\
\cline { 2 - 7 } & Average Power (kW) & Energy (kWh) & Average Power (kW) & Energy (kWh) & Average Power (kW) & Energy (kWh) \\
\hline Sunny & 2.96 & 21 & 2.93 & 20.6 & 2.24 & 15.1 \\
\hline Cloudy & 2.83 & 19 & 2.78 & 18.6 & 2.17 & 13.9 \\
\hline Rainy & 3.05 & 17.6 & 3.02 & 17.1 & 2.47 & 12.6 \\
\hline
\end{tabular}

Table 2. Energy and efficiency of solar panel in various weather conditions.

\begin{tabular}{|c|c|c|c|c|c|c|}
\hline \multirow{3}{*}{ Weather } & \multicolumn{3}{|c|}{ Solar Panel } & \multicolumn{2}{c|}{ Thin-Film } \\
\cline { 2 - 7 } & \multicolumn{2}{|c|}{ Monocrystalline } & \multicolumn{2}{c|}{ Polycrystalline } & \multicolumn{2}{c|}{ (\%) } \\
\cline { 2 - 7 } & Energy (kWh) & Efficiency (\%) & Energy (kWh) & Efficiency (\%) & Energy (kWh) & Efficiency (\%) \\
\hline Sunny & 21 & 100 & 20.6 & 100 & 15.1 & 100 \\
\hline Cloudy & 19 & 90.48 & 18.6 & 90.29 & 13.9 & 92.05 \\
\hline Rainy & 17.6 & 83.81 & 17.1 & 83.01 & 12.6 & 83.44 \\
\hline
\end{tabular}




\section{CONCLUSION}

Results from the study reveals that thin-film type solar panel is not suitable for solar rooftop system due to generating capacity less than other types of solar panels under the same installation area. Monocrystalline and polycrystalline solar panel can generate average power and energy relatively similar. In term of solar panel performance under various weather conditions, thin-film has better efficiency in cloudy and rainy day compared with other types of solar panel. For solar rooftop system weather condition is one of the factors needed to be taken into account when calculating economic cost due to its significant impact on power generating capacity.

\section{References}

(1) Department of Alternative Energy Development and Efficiency, Areas with solar power potential Online Avaiable http://weben.dede.go.th/webmax/content/areas-solar-power-potential

(2) M. Koussa, and S. Djohra : "Long term PV system performances estimating by using only the main weather parameters data. Case of study: An Algerian Temperate climate," 5th International Renewable Energy Congress (IREC), pp. 1-6, 25-27 March 2014.

(3) M. Koussa, S. Hadji, and D. Saheb : "Long-term PV system performances evaluation by only the main weather parameters data uses. Case of study: Desert and arid climate," International
Renewable and Sustainable Energy Conference (IRSEC), pp. 252257, 17-19 Oct. 2014

(4) N.G. Dhere, A. Kaul, S.A. Pethe : "Long-term performance study of united solar PV modules in hot and humid climate of Florida," 37th IEEE Photovoltaic Specialists Conference (PVSC), pp. 003119003122, 19-24 June 2011.

(5) J. Ordóñez, E. Jadraque, J. Alegre, and G. Martínez: "Analysis of the photovoltaic solar energy capacity of residential rooftops in Andalusia (Spain)," Renewable and Sustainable Energy Reviews, Vol. 14, No. 7, pp. 2122-2130, September 2010.

(6) L. Ko, J.C. Wang, C.Y. Chen, and H.Y. Tsai : "Evaluation of the development potential of rooftop solar photovoltaic in Taiwan," Renewable Energy, Vol. 76, pp. 582-595 April 2015.

(7) Jung Hus So, Hye Mi Hwang, Byung Gyu Yu, Jin Su Yoo, Gwon Jong Yu, and Ju-Yeop Choi : "Comparison analysis of measured and estimated yield of grid-connected PV system," 35th IEEE Photovoltaic Specialists Conference (PVSC), pp. 002291-002294, 20-25 June 2010.

(8) A. Zahedi : "Developing a method to accurately estimate the electricity cost of grid-connected solar PV in Bangkok," International Conference and Utility Exhibition on Green Energy for Sustainable Development (ICUE), pp. 1-4, 19-21 March 2014.

(9) A. Phowan, P. Sripadungtham, A. Limmanee, and E. Hattha : "Performance analysis of polycrystalline silicon and thin film amorphous silicon solar cells installed in Thailand by using simulation software," 8th International Conference on Electrical Engineering/Electronics, Computer, Telecommunications and Information Technology (ECTI-CON), pp.625-628, 17-19 May 2011.

(10) K. Thongpao, P. Sripadungtham, P. Raphisak, K. Sriprapha, and E. Hattha : "Outdoor performance of polycrystalline and amorphous silicon solar cells based on the influence of irradiance and module temperature in Thailand," International Conference on Electrical Engineering/Electronics Computer Telecommunications and Information Technology (ECTI-CON), pp. 74-77, 19-21 May 2010. 